Research Article

\title{
Cross-Border Internet of Things E-Commerce Warehouse Control System Based on TRIZ Theory
}

\author{
Tingting Liu \\ Henan Institute of Economics and Trade, Zhengzhou, 450018, China \\ Correspondence should be addressed to Tingting Liu; liutingting@henetc.edu.cn
}

Received 9 November 2021; Revised 23 November 2021; Accepted 30 November 2021; Published 18 December 2021

Academic Editor: Tongguang Ni

Copyright (c) 2021 Tingting Liu. This is an open access article distributed under the Creative Commons Attribution License, which permits unrestricted use, distribution, and reproduction in any medium, provided the original work is properly cited.

\begin{abstract}
Cross-border e-commerce of the Internet of Things is affected by international situations and political factors. Supply chain interruption and returns will cause violent fluctuations in commodity inventory, making the inventory control of cross-border e-commerce very difficult. The TRIZ principle is utilized to solve the problem of the difficulty to evaluate the suppliers comprehensively in e-commerce warehouse management. The Markov algorithm is used to describe the change of inventory level. The cyclic expected time and cost function are constructed by the horizontal crossing method, updating the process and Martingale theory. The effect of the correlation between the demand and supply interruption on the optimal inventory control strategy is studied by simulation. The change of the optimal control strategy under the different interrupt and return types is analyzed, and the validity of the management system is verified.
\end{abstract}

\section{Introduction}

The accelerated evolution of cross-border Internet of Things e-commerce has become a new trend of international trade development and a novel engine of national economic growth [1]. To promote the development of cross-border e-commerce, the government encourages the establishment of a comprehensive service system for cross-border e-commerce. At present, the Internet of Things technology is developing rapidly, and the market scale is also in a good situation of expanding. The Internet of Things has turned into an important development strategy for countries around the world. The government has made many policies and plans to promote the in-depth development of the Internet of Things technology so that the industrial system of the Internet of Things constantly improved.

The environment of cross-border Internet of Things e-commerce is increasingly complex, which can be summarized as influenced by three factors. Firstly, the international situations and political factors result in supply disruptions [2]. Secondly, it is affected by the international epidemic, bad weather, and traffic jams [3]. Moreover, the new consumer-related laws and regulations require "seven days without reason to return goods," resulting in a large number of returned goods. These factors interact to create wild swings in inventories. Consequently, the companies increase the costs while reducing the quality of service. Therefore, how to effectively control the inventory under this environment has become a research hotspot in recent years.

Literature [4] studies the joint order decision of retailer optimal pricing when the order demand is out of stock due to price changes. Literature [5] studies the optimal pricing and ordering of the supply chain and its members when the market demand of the products depends on the price and consumers' time preference. Literature [6] constructed a multivariety-combined replenishment inventory model with the demand dependent on the deterioration time based on the characteristics of the nonimmediate deterioration of the products. In the above literature on perishable inventory strategy, the price decision alone was considered, while the replenishment cycle was out of consideration. In some inventory systems, such as the fashion goods inventory, when the goods are out of stock, the length of waiting time for each replenishment will directly affect whether the consumers can accept the delayed arrival of goods. Some 
scholars have conducted in-depth studies on the combination of the replenishment cycle and pricing. Literature [7] considers the demand dependence of nonimmediate perishable products on the price and product quality and studies the joint decision of the optimal price and replenishment cycle. Literature [8] assumes that price is a time-varying function of the discount rate and initial price, and the demand rate depends on the price and product quality. It studies stock replenishment and pricing decisions for perishable products. The above literature does not consider the impact of the price changes of perishable products during the sales period. Literature [9] analyzes the impact of price discount before product deterioration on unit profit. Others have studied retailers' promotional efforts on perishable goods. Literature [10] takes dynamic pricing, promotion efforts, and delayed payment of the perishable products into consideration and constructs a corresponding joint decision model of ordering and pricing. Literature [11] established a two-stage ordering decision model of dynamic perishable goods sellers to study the ordering decision of the sellers. Literature [12] studies the joint pricing and replenishment of nonimmediate deterioration products on the basis of considering the promotion efforts, price-sensitive random demand rate, and partial delayed order.

People often adopt the inventory defense strategy [13] in addition to the combination of multisource ordering [14] and other means to cope with supply interruptions. Literature [15] evaluated the defensive effects of various strategies. Literature [16], after summarizing the achievements made in the past 20 years, points out that the interruption problem related to the demand and supply state needs to be solved urgently. In this regard, literature [17] studied the use of product substitution strategy to alleviate the panic buying caused by interruptions. To deal with the impact of returned goods on inventory, researchers also put forward many effective measures. Literature [18] studies the inventory control problem in an unrelated environment of return and supply interruption. In addition, for special returns, literature [19] studied the design of the closed-loop supply chain network under the interruption of supply facilities.

Supplier selection is one of the main contents of e-commerce warehouse management. When choosing the suppliers, it is easy to be influenced by the emotional factors of the decision makers. Therefore, there is no quantitative standard for supplier evaluation, and it is difficult to achieve reasonable, objective, and comprehensive evaluation. If e-commerce warehouse management is to continue to develop efficiently and reliably, it is necessary to establish a set of scientific and effective evaluation systems for supplier selection and decision-making. The innovations and contributions of this paper are listed below.

(1) Based on the TRIZ (theory of the solution of inventive problems) theory, this paper makes an indepth analysis of the e-commerce warehouse management supplier selection to solve the inventory control problem in the environment related to demand and return and supply status.
(2) TRIZ principle is used to solve the problem that it is difficult to evaluate suppliers comprehensively in e-commerce warehouse management.

(3) As the parameters of the Markov modulation model depend on the Markov chain, they are changeable. It allows the pricing models to change with market conditions for better reflecting the objective reality. Thus, Markov is used to describe the change of the inventory level, and the horizontal crossing method and multidimensional martingale theory are used to study the construction of the model. On this basis, the new environment of inventory management enlightenment is put forward by the analysis of the influence of key factors.

The chapter structure of this paper is as follows: the TRIZ theory is described in the next section. The third part mainly introduces the algorithm model proposed in this paper. The fourth part is experiment and analysis. The fifth part is the conclusion.

\section{TRIZ Theory}

TRIZ is the theory of creative problem solving. It is a set of invention and creation theories put forward by the former Soviet Union's Achishuler and his colleagues in 1946 [20]. For this reason, Achishuler is also known as the "Father of TRIZ." After years of continuous research by enterprises and scholars, the TRIZ theory has formed a systematic theory to solve invention problems, which is shown in Figure 1.

The content system of TRIZ theory mainly includes the following contents.

\subsection{Theoretical Basis}

(a) Technical systems: It refers to anything that performs or performs a function. A technical system generally has multiple subsystems, and each subsystem is a technical system in its own right. The subsystems of a technical system interact with each other, and changing one subsystem will inevitably affect the whole system.

(b) Conflict is a contradiction: It is another core concept of the TRIZ theory. The TRIZ theory holds that creative problem solving must solve at least one pair of conflicts. In the TRIZ theory, conflict is divided into three categories, namely technical conflict, physical conflict, and management conflict. Technology conflict refers to the deterioration of another feature or parameter when one feature or parameter is improved. Physical conflict refers to two opposite states of a technical system at the same time on a certain characteristic or parameter. Managing conflict is when something needs to be done to achieve certain results or avoid certain phenomena. However, not knowing how to do that means not being able to distinguish between technical conflict and physical conflict. 


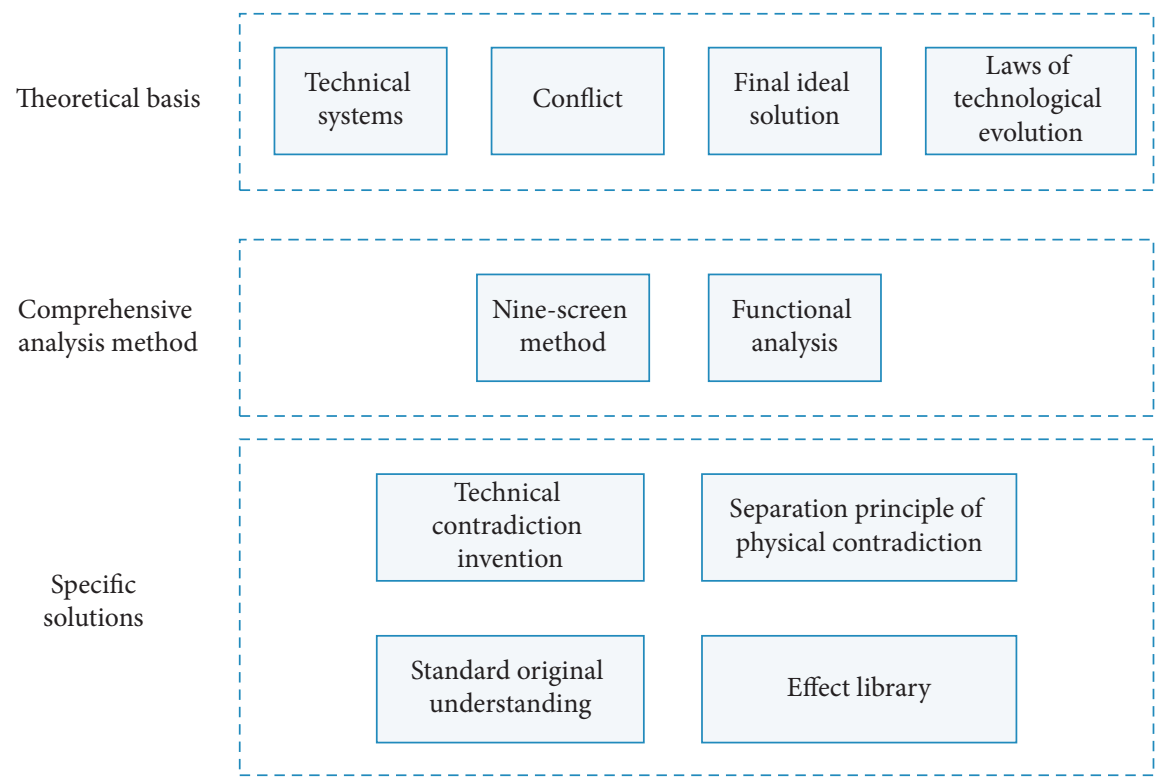

FiguRE 1: TRIZ system of theory.

(c) Final ideal solution: It refers to a technical system. If it tends to use fewer resources, more features will be provided with fewer side effects. It is a state that tends to be more ideal. The TRIZ theory holds that there is no perfectly ideal technology system. However, the desired end result can be a signpost for innovation. It makes the "ideality" of the technical system increase continuously and gets closer to the final ideal solution state.

(d) The laws of technological evolution: Every technological system is in a state of evolution, in the sense that things are constantly evolving and changing. Achishuler proposed eight rules of evolution. These evolutionary laws can predict the evolution of technological systems, effectively increasing our predictability and moving in their direction.

\subsection{Comprehensive Analysis Method}

(a) Nine-screen method: It refers to considering not only the current system but also its supersystems and subsystems when analyzing and solving problems. The past and future of the current system are considered. Also, the past and future of the hypersystems and subsystems are taken into account.

(b) Functional analysis: It refers to the technical system as a unit from the perspective of realizing the functions and fully analyzes the system, subsystem, super system, and their internal relations or functions.

\subsection{Specific Solutions}

(a) Technical contradiction invention principle: It refers to the 40 principles of creation summarized by Achishuler according to the categories of technological contradictions. After the main contradiction is obtained based on the contradiction analysis, it can be solved according to the creation principle corresponding to the contradiction matrix table. There are four main steps to define a technical contradiction. Step one is to know what the problem is. Step two is to know what the existing solutions are. The third step is to identify the shortcomings of the existing solution. The fourth step is to know what is improved and what is worsened, i.e., a pair of technical contradictions are formed.

(b) Separation principle of physical contradiction: It mainly has four separation principles to solve the physical contradiction problems. The four separation principles are space separation principle, time separation principle, conditional separation principle, and whole and part separation principle.

(c) Standard original understanding: It is a construction rule for combining and reorganizing the technical systems. Two functions are contained. One is to help improve an existing system or synthesize a new system. The second is the most effective method to establish the graphical model of the problem, namely the object-field model.

(d) Effect library: In the process of analyzing patents, Achishuler used the principles for many of his existing inventions borrowed from the other fields of scientific knowledge. Therefore, one of the methods proposed in the TRIZ theory to solve the problem is the knowledge base. It means applying the relevant laws of the field, especially in other fields, to solve problems.

\section{3. e-Commerce Warehouse Control System of Internet of Things}

3.1. Supplier Selection Model. There are many factors influencing the selection of e-commerce warehouse 
management suppliers. Combined with the general characteristics of e-commerce warehouse management, this paper chooses factors that are easy to measure to evaluate suppliers according to the extraction principle in the 40 invention principles of the TRI billion theory system. Supplier evaluation is mainly carried out from five aspects: product quality, product price, supplier's technical ability, supplier's management ability, and supplier's service ability. Associated with the invention principles of the TRIZ theory system, the evaluation indexes of the five aspects of the supplier selection are determined, and the supplier selection evaluation model is constructed.

Firstly, according to the universal invention principle of the TRIZ theory, the judgment matrix $G$ of the supplier selection evaluation system is constructed. The product quality $\mathrm{H} 1$, product price $\mathrm{H} 2$, supplier's technical ability $\mathrm{H} 3$, supplier's management ability $\mathrm{H} 4$, and supplier's service ability $\mathrm{H} 5$ of the four suppliers $(\mathrm{C} 1 \sim \mathrm{C} 4)$ are compared in pairs. Their relative importance is judged, and the values of each parameter of the judgment matrix $G$ are listed according to the judgment results. The same method is applied to construct the judgment matrix of H1 H5. Taking the judgment matrix $G$ of the supplier selection evaluation system as an example, the judgment matrix has the following characteristics:

$$
\begin{aligned}
G_{x x} & =1, \\
G_{y x} & =\frac{1}{G_{x y}}, \\
G_{x y} & =\frac{G_{x z}}{G_{y z}}, \quad(x, y, z=1,2, \ldots \ldots t) .
\end{aligned}
$$

The maximum feature roots and feature vectors of $G, H 1$, $\mathrm{H} 2, \mathrm{H} 3, \mathrm{H} 4$, and $\mathrm{H} 5$ of the supplier selection evaluation system are determined by the combined invention principle of the TRIZ theory. The vector of the judgment matrix $G$ of the supplier selection evaluation system is normalized as follows:

$$
G_{x y}=\frac{G_{x}}{\sum_{1}^{t} G_{y}}, \quad(x, y=1,2, \ldots, t) .
$$

Each column of the supplier selection evaluation system judgment matrix is normalized, and the judgment matrix is obtained.

$$
X_{x}=\sum_{1}^{t} G_{x y}, \quad(x=1,2, \ldots, t) .
$$

Divide the vector after adding the judgment matrices of the supplier selection evaluation system by $n$ to obtain the weight vector.

$$
M=\frac{X_{x}}{t} .
$$

The calculation will judge the maximum characteristic root $\lambda_{\max }$ of the matrix.

$$
\lambda_{\max }=\sum_{1}^{t} \frac{(\mathrm{HX})_{x}}{t X_{x}} .
$$

Combined with the homogeneity invention principle of the TRIZ theory, the consistency test of the judgment matrix of the supplier selection evaluation system is carried out. If the test fails, the model should be rebuilt or the judgment matrix should be reconstructed.

The consistency index CI of the judgment matrix is

$$
\mathrm{CI}=\frac{\lambda_{\max }-t}{t-1} \text {. }
$$

$\mathrm{CI}=0$ indicates that the judgment matrix has complete consistency. CI is close to 0 , indicating that the judgment matrix has a satisfactory consistency. The larger the CI, the more serious the inconsistency of the judgment matrix.

Calculate the consistency ratio $\mathrm{CR}$ of the judgment matrix of the supplier selection evaluation system.

$$
\mathrm{CR}=\frac{\mathrm{CI}}{\mathrm{RI}} \text {. }
$$

When CR $<0.1$, it indicates that the judgment matrix of the product quality has a satisfactory consistency.

When $C R \geq 0.1$, it indicates that the judgment matrix of the product quality should be rebuilt.

Using the feedback invention principle of the TRIZ theory, the optimal scheme is selected by calculation. Furthermore, synthesize the pros and cons of the last level of the order.

$$
W=\sum_{g}^{h} X_{x} \times X_{x}^{x} .
$$

The final calculation result is the comprehensive score of the evaluation of the supplier in five aspects: product quality, product price, technical ability, management ability, and service ability. The supplier with the highest score is the best supplier choice.

\subsection{Warehouse Control System}

3.2.1. Problem Description. Assume that a retailer sells a product and accepts returns. Set return without defect after repackaging into the stock as new products to meet the needs of users. The supply state change is described by the state transition of irreducible continuous time Markov chain $Y=\{Y(n), n \geq 0\}$. Here, $Y$ has two states. $Y(n)=1(Y(n)=2)$ indicates that the time $t$ supplier is in the supply (interrupted) state. Its duration obeys the exponential distribution of $\theta_{1}\left(\theta_{2}\right)$. To obtain the analytical solution, the user demand rate during this period is set as $\mu_{1}\left(\mu_{2}\right)$. The return is a compound Poisson process with the arrival rate $\lambda_{1}\left(\lambda_{2}\right)$, and the batch size follows an exponential distribution with the independent parameter $q_{1}\left(q_{2}\right)$.

Continuous inventory $(\mathrm{r}, \mathrm{C})$ strategy is adopted for ordering, i.e., start ordering when the inventory reaches $r$ 
level. Assume that the lead time is 0 . If $Y=1$, then the supplier immediately replenishes the inventory to level C. If $Y=2$, the retailer needs to wait until the supplier outage ends before replenishing the inventory to level C. During the operation of the system, if the inventory level is 0 , the demand is lost, resulting in out-of-stock costs. If the return exceeds the limit of the inventory capacity $\mathrm{C}$, the retailer will exceed the part of the discount, and the processing time will be ignored. The return fee (including product cost and packaging replacement fee), handling fee, out-of-stock fee, and inventory fee per unit time are $c_{r}, c_{d}, c_{\pi}$ and $c_{a}$, respectively. The fixed and variable costs of the order are $c_{f}$ and $c_{o}$, respectively. Determine $r$ and $\mathrm{C}$ to minimize the retailer's long-run average total expense ratio.

3.2.2. Model Construction. According to the problem description, the inventory level $I(n)$ is a Markov-modulated Levy process starting from $\mathrm{C}$.

$$
\begin{aligned}
I(n) & =C-Q(n) \\
& =C-\sum_{y=1}^{2} \int_{0}^{n} Q_{y}(\tau) 1_{\{Y(\tau)=y\}} \mathrm{d} \tau, Q_{y}(\tau) \\
& =\mu_{y}-\sum_{t=1}^{T_{y}(\tau)} D_{t}^{y},
\end{aligned}
$$

$T_{y}(\tau)$ is a Poisson process, indicating that it returns to the batch at time $\tau$. $D_{1}^{y}, D_{2}^{y}, \ldots$ is the independent exponential distribution sequence of the $q_{y}$ parameter and represents the quantity of the returned goods in each batch.

To facilitate the determination of the amount of returned goods, the remaining inventory space process $M(n)$ is analyzed below. Since the returns beyond $\mathrm{C}$ are processed, $\mathrm{W}$ can be represented as a Markov-modulated Levy process reflected at 0 .

$$
\begin{aligned}
M(n) & =C-I(n)+L(n) \\
& =Q(n)+L(n) .
\end{aligned}
$$

Here, the local time process $L_{y}$ gives us the amount of returned goods processed up to time T. Obviously, the process in state $J$ is zero.

$$
L_{y}(n)=\int_{0}^{n} 1_{\{Y(s)=y\}} \mathrm{d} L(s),
$$

where $L(n)=L_{1}(n)+L_{2}(n)$. It can be seen from the strong Markov property of Levy process that $M$ is a renewal process. Update the optional interrupt end point at which the supplier completes replenishment.

If $M_{1}$ is defined as a subloop running from level 0 to level $\mathrm{C}$, then a loop of $M_{1}$ may have multiple subloops embedded in it. If the number of subcycles is $T$, it can be known from the strong Markov property of Levy process that $\mathrm{N}$ follows geometric distribution. Let the running time of the subcycle be $\tau_{1}$ and the probability that process $M_{1}$ reaches the level C corresponding to a state $y$ be $u_{y}$.

$$
\begin{aligned}
\tau_{1} & =\inf \left\{n>0: M_{1}(n)=\bar{C} \mid M_{1}(0)=0, Y(0)=1\right\}, \\
u_{y} & =U\left(Y\left(\tau_{1}\right)=y\right), \quad y=1,2 .
\end{aligned}
$$

The expected number of subcycles is $E[T]=1 / u_{2}$. The expected time of the $M_{1}$ cycle is as follows:

$$
\begin{aligned}
E\left[N_{1}\right] & =E\left[\tau_{1}\right] E[T] \\
& =\frac{E\left[\tau_{1}\right]}{u_{2}} .
\end{aligned}
$$

In addition, let the cycle time of $M_{2}$ be $N_{2}$, and it can be seen from the description of the problem that $\mathrm{N}_{2}$ follows an exponential distribution with parameters $\theta_{2}$. Thus, the expected time of a cycle of process $M$ is as follows:

$$
\begin{aligned}
{[N] } & =E\left[N_{1}\right]+E\left[N_{2}\right] \\
& =\frac{E\left[\tau_{1}\right]}{u_{2}}+\frac{1}{\theta_{2}} .
\end{aligned}
$$

The cost function of building the system according to the operation of $M$ is as follows:

(1) Inventory cost function: According to the limit theorem of the renewal process, the stationary distribution function of $M_{1}$ and $M_{2}$ exists and is set as $M_{1, e}$ and $M_{2, e}$, respectively. The expected inventory cost of a cycle is as follows:

$E[\mathrm{CB}]=c_{b}\left\{\left(C-E\left[M_{1, e}\right]\right) \frac{E\left[\tau_{1}\right]}{u_{2}}+\frac{\left(C-E\left[M_{2, e}\right]\right)}{\theta_{2}}\right\}$.

(2) Return cost function: since return is a compound Poisson process, the amount of return per unit time is equal to the sum of the product of the amount of return per state and the corresponding state's longrange time. The expected return cost of a cycle is as follows:

$$
E[\mathrm{CR}]=c_{r}\left\{\frac{\lambda_{1}}{q_{1}} \frac{\theta_{2}}{\theta_{1}+\theta_{2}}+\frac{\lambda_{2}}{q_{2}} \frac{\theta_{1}}{\theta_{1}+\theta_{2}}\right\} E[N] .
$$

(3) Deal with the cost function: For phase 1, the desired return processing amount for state $y$ is $\ell_{y}$. For phase 2 , where the amount of returned goods is $E[\Gamma]$, the expected return processing the cost for a cycle is as follows:

$$
\begin{aligned}
E[\mathrm{CD}] & =\& c_{d}\left\{E\left[L\left(\tau_{1}\right)\right] E[T]+E[\Gamma]\right\} \\
& =c_{d}\left\{\frac{\left(\ell_{1}+\ell_{2}\right)}{u_{2}}+E[\Gamma]\right\} .
\end{aligned}
$$

(4) Shortage cost function: Shortages occur only in stage 2 , and given $E[\Pi]$ as expected shortages, the expected shortage costs for a cycle are as follows:

$$
E[\mathrm{CS}]=c_{\pi} E[\Pi] .
$$


(5) Replenishment cost function: The replenishment amount of stage 1 subcycle is $\bar{C}$. Assume that the inventory level before the end of stage 2 is $M_{2}\left(N_{2^{-}}\right)$. Then, the replenishment quantity is $E\left[M_{2}\left(N_{2^{-}}\right)\right]$. The expected replenishment cost for a cycle is as follows:

$$
E[\mathrm{CO}]=\frac{c_{f}}{u_{2}}+c_{o}\left\{\frac{\bar{C} u_{1}}{u_{2}}+E\left[M_{2}\left(N_{2^{-}}\right)\right]\right\} .
$$

Based on the renewal reward theorem, the long-term average expense ratio model is constructed as follows:

$$
\mathrm{NC}(r, C)=\frac{E[\mathrm{CB}]+E[\mathrm{CR}]+E[\mathrm{CD}]+E[\mathrm{CS}]+E[\mathrm{CO}]}{E[N]} .
$$

3.2.3. Determination of Functions in the Model. Since $M_{1}$ and $M_{2}$ are Markov-modulated Levy processes, it is difficult to obtain the undetermined functions by traditional methods. Kella-Whitt martingale is an effective tool for solving the Levy process problems.

Let $\mathrm{Q}(\mathrm{n})$ be a Markov-modulated Levy process. If $K(n)=Q(n)+J(n)$, the equation obtained is as follows:

$$
W(\alpha, n)=\int_{0}^{n} e^{\alpha K(s)} 1_{Y(s)} \mathrm{d} s F(\alpha)+e^{\alpha K(0)} 1_{Y(0)}-e^{\alpha K(n)} 1_{Y(n)}+\alpha \int_{0}^{n} e^{\alpha K(s)} 1_{Y(s)} \mathrm{d} J(s) .
$$

It is the 0 mean (row) vector martingale, where $1_{Y}$ is an $\mathrm{N}$-dimensional row vector whose $\mathrm{y}^{\text {th }}$ component is 1 and remainder is $0 . F(\alpha)=V+\operatorname{diag}\left(\varphi_{1}(\alpha), \ldots, \varphi_{n}(\alpha)\right)$ is the matrix exponent of $\mathrm{Q}(\mathrm{n})$. $\mathrm{V}$ is the state transfer rate matrix of $y . \varphi_{1}(\alpha)$ is the Levy index of $Q_{y}(n)$.
For this problem, if $J(n)=L(n)$, then $K(n)=M_{1}(n)$. The process $\mathrm{L}(\mathrm{n})$ only changes when $M_{1}(n)=0$, and hence, it is simplified as follows:

$$
W(\alpha, n)=\int_{0}^{n} e^{\alpha M_{1}(s)} 1_{Y(s)} \mathrm{d} s F(\alpha)+e^{\alpha M_{1}(0)} 1_{Y(0)}-e^{\alpha M_{1}(n)} 1_{Y(n)}+\alpha \int_{0}^{n} 1_{Y(s)} \mathrm{d} L(s) .
$$

Therefore, we can get,

$$
\begin{aligned}
V & =\left[\begin{array}{cc}
-\theta_{1} & \theta_{1} \\
\theta_{2} & -\theta_{2}
\end{array}\right], \quad \varphi_{y}(\alpha) \\
& =\operatorname{loa} E e^{\alpha \mathrm{Q}_{y}(n)} \\
& =\mu_{y} \alpha-\frac{\lambda_{y} \alpha}{\left(q_{y}+\alpha\right)}
\end{aligned}
$$

The matrix exponentials are as follows:

$$
F(\alpha)=\left[\begin{array}{cc}
-\theta_{1}+\varphi_{1}(\alpha) & \theta_{1} \\
\theta_{2} & -\theta_{2}+\varphi_{2}(\alpha)
\end{array}\right] .
$$

The Kella-Whitt martingale described above is used to determine the function to be solved. Firstly, the optimal sampling theorem for $\tau_{1}$ is obtained from equation (22).

$$
E \int_{0}^{\tau_{1}} e^{\alpha M_{1}(n)} 1_{Y(n)} \mathrm{d} n F(\alpha)+E e^{\alpha M_{1}(0)} 1_{Y(0)}-E e^{\alpha M_{1}\left(\tau_{1}\right)} 1_{Y\left(\tau_{1}\right)}+\alpha E \int_{0}^{\tau_{1}} 1_{Y(n)} \mathrm{d} L(n)=0 .
$$

By $\operatorname{det}(F(\alpha))=0$, four roots $\alpha_{w}$ can be obtained, satisfying the right column vector $F\left(\alpha_{w}\right) h^{[w]}=0$ right column vector. In equation (25), take $\alpha=\alpha_{w}$ and multiply with $h^{[w]}$.

$$
b_{1}^{[w]}-e^{\alpha_{w} \bar{C}}\left(u_{1} b_{1}^{[w]}+u_{2} b_{2}^{[w]}\right)+\alpha_{w}\left(\ell_{1} b_{1}^{[w]}+\ell_{2} b_{2}^{[w]}\right)=0,
$$

where $w=1,2,3,4$. To solve this equation, it can be obtained as follows:

$$
\left[u_{1}, u_{2}, \ell_{1}, \ell_{2}\right]^{N}=H^{-1} \phi
$$

Among them,

$$
\begin{aligned}
& \phi=\left[b_{1}^{[1]}, b_{1}^{[2]}, b_{1}^{[3]}, b_{1}^{[4]}\right]^{N}, \\
& H=\left[\begin{array}{cccc}
b_{1}^{[1]} e^{\alpha_{1} \bar{C}} & b_{1}^{[1]} e^{\alpha_{1} \bar{C}} & -\alpha_{1} b_{1}^{[1]} & -\alpha_{1} b_{2}^{[1]} \\
b_{1}^{[2]} e^{\alpha_{2} \bar{C}} & b_{2}^{[2]} e^{\alpha_{2} \bar{C}} & -\alpha_{2} b_{1}^{[2]} & -\alpha_{2} b_{2}^{[2]} \\
b_{1}^{[3]} e^{\alpha_{3} \bar{C}} & b_{2}^{[3]} e^{\alpha_{3} \bar{C}} & -\alpha_{3} b_{1}^{[3]} & -\alpha_{3} b_{2}^{[3]} \\
b_{1}^{[4]} e^{\alpha_{4} \bar{C}} & b_{2}^{[4]} e^{\alpha_{4} \bar{C}} & -\alpha_{4} b_{1}^{[4]} & -\alpha_{4} b_{2}^{[4]}
\end{array}\right] .
\end{aligned}
$$


Then, using the obtained $u_{y}$ and $\ell_{y}$, simplified for (25), it can be obtained as

$$
E \int_{0}^{\tau_{1}} e^{\alpha M_{1}(n)} 1_{Y(n)} \mathrm{d} n F(\alpha)=\left[\psi_{1}(\alpha), \psi_{2}(\alpha)\right] .
$$

Substitute $F(\alpha)$ given in equation (22) into equation (29) and obtain

$$
E \int_{0}^{\tau_{1}} e^{\alpha M_{1}(n)} 1_{\{Y(n)=y\}} \mathrm{d} n=\frac{\psi_{y}(\alpha) \varphi_{x}(\alpha)-\theta_{x}\left(\psi_{1}(\alpha)+\psi_{2}(\alpha)\right)}{\varphi_{1}(\alpha) \varphi_{2}(\alpha)-\theta_{1} \varphi_{2}(\alpha)-\theta_{2} \varphi_{1}(\alpha)} .
$$

Let $\alpha \longrightarrow 0$ in equation (30), and apply L'Hopital's rule on the right side of the equation.

$$
E \int_{0}^{\tau_{1}} 1_{\{Y(n)=y\}} \mathrm{d} n=\frac{\theta_{x}\left(\bar{C}-\ell_{1}-\ell_{2}\right)-(-1)^{y} u_{2}\left(\mu_{x}-\lambda_{x} / q_{x}\right)}{\theta_{1}\left(\mu_{2}-\lambda_{2} / q_{2}\right)+\theta_{2}\left(\mu_{1}-\lambda_{1} / q_{1}\right)} .
$$

It can be obtained from equation (31).

$$
E\left[\tau_{1}\right]=E \int_{0}^{\tau_{1}} 1_{\{Y(n)=1\}} \mathrm{d} n+E \int_{0}^{\tau_{1}} 1_{\{Y(n)=2\}} \mathrm{d} n=\frac{\left(\theta_{1}+\theta_{2}\right)\left(\bar{C}-\ell_{1}-\ell_{2}\right)+u_{2}\left(\mu_{2}-\mu_{1}+\lambda_{1} / q_{1}-\lambda_{2} / q_{2}\right)}{\theta_{1}\left(\mu_{2}-\lambda_{2} / q_{2}\right)+\theta_{2}\left(\mu_{1}-\lambda_{1} / q_{1}\right)} .
$$

In addition, the number of $M_{1}$ subcycles in time $\tau_{1}$ obeys geometric distribution.

$$
E \int_{0}^{N_{1}} e^{\alpha M_{1}(n)} \mathrm{d} n=\frac{E \int_{0}^{\tau_{1}} e^{\alpha M_{1}(n)} \mathrm{d} n}{u_{2}} .
$$

Using the ergodic theorem and equation (33), it can be obtained.

$$
E\left[e^{\alpha M_{1, e}}\right]=\frac{E \int_{0}^{N_{1}} e^{\alpha M_{1}(n)} \mathrm{d} n}{E\left[N_{1}\right]}=\frac{\sum_{y=1}^{2} E \int_{0}^{\tau_{1}} e^{\alpha M_{1}(n)} 1_{\{Y(n)=y\}} \mathrm{d} n}{E\left[\tau_{1}\right]} .
$$

The value can be determined by substituting equations (30) and (32) into (34). On this basis, it can be obtained.

$$
E\left[M_{1, e}\right]=\left.\frac{\mathrm{d}}{\mathrm{d} \alpha}\left\{E\left[e^{\alpha M_{1, e}}\right]\right\}\right|_{\alpha=0^{0}}
$$

Equation (35) is easy to be obtained using equation (34), however, the result is long and tedious. Considering space limitation, it is omitted here.

Process $M_{2}$ is a Levy process that starts from level $\mathrm{C}$ and runs in interval $[0, \mathrm{C}]$. The expectation of steady-state $M_{2}$ is zero. It can be obtained as follows:

$$
\begin{aligned}
E\left[M_{2, e}\right] & =U_{0} C+\int_{0}^{\bar{C}} \operatorname{if}_{2}(i) \mathrm{d} i+\int_{\bar{C}}^{C} \operatorname{if}_{1}(i) \mathrm{d} i \\
& =U_{0} C+\sum_{y=1}^{2}\left\{\left[\left(C-\frac{1}{\omega_{y}}\right) e^{\omega_{y} C}-\left(\bar{C}-\frac{1}{\omega_{y}}\right) e^{\omega_{y} \bar{C}}\right] \frac{G_{y}}{\omega_{y}}+\left[\left(\bar{C}-\frac{1}{\omega_{y}}\right) e^{\omega_{y} \bar{C}}+\frac{1}{\omega_{y}}\right] \frac{H_{y}}{\omega_{y}}\right\} .
\end{aligned}
$$

\section{Experiment}

4.1. Simulation Experiment of Supplier Selection. The four alternative suppliers of commodity $Z$ are C1, C2, C3, and C4. The relative weight of each indicator is given by experts according to the importance scale. Construct the judgment matrix of supplier choice A, product quality $\mathrm{H} 1$, product price $\mathrm{H} 2$, supplier's technical ability $\mathrm{H} 3$, supplier's management ability $\mathrm{H} 4$, and supplier's service ability $\mathrm{H} 5$. Construct the judgment matrix of $\mathrm{C} 1, \mathrm{C} 2, \mathrm{C} 3$, and $\mathrm{C} 4$ relative to the product qualification rate $\mathrm{H} 11$, raw material supply condition H12, product production equipment, and product inspection equipment condition $\mathrm{H} 3$. The judgment matrix of the supplier choice $G$ and its weight are shown in
Table 1. The judgment matrix of product quality $\mathrm{H} 1$ and its weight are shown in Table 2.

The supplier selection judgment matrix and its weight are calculated, and the consistency of the constructed judgment matrix is tested. By the analysis of the calculation results, the values of $\mathrm{CI}$ and $\mathrm{CR}$ are less than 0.1. It shows that the constructed judgment matrix has a satisfactory consistency. According to the calculation, the total score of supplier C1 is 0.2623 . The total score of supplier C2 was 0.3044 . The total score of supplier C3 was 0.2074 . The total score of supplier $\mathrm{C} 4$ was 0.2259 . Therefore, the four suppliers of commodity A should be selected in priority order: (1) C2, (2) C1, (3) C4, and (4) C3. Therefore, supplier C2 should be selected as the supplier of commodity $Z$. 
TABLe 1: Supplier selection judgment matrix $G$ and its weight.

\begin{tabular}{lcccccc}
\hline G & H1 & H2 & H3 & H4 & H5 & M1 \\
\hline H1 & 1 & 2 & 3 & 3 & 4 & 0.4033 \\
H2 & $1 / 2$ & 1 & 2 & 2 & 3 & 0.2458 \\
H3 & $1 / 3$ & $1 / 2$ & 1 & 1 & 2 & 0.1384 \\
H4 & $1 / 3$ & $1 / 2$ & 1 & 1 & 2 & 0.1354 \\
H5 & $1 / 4$ & $1 / 3$ & $1 / 2$ & $1 / 2$ & 1 & 0.0771 \\
\hline
\end{tabular}

TABle 2: Product quality judgment matrix $\mathrm{H}$ and its weight.

\begin{tabular}{lccccc}
\hline $\mathrm{H}$ & $\mathrm{H} 11$ & $\mathrm{H} 12$ & $\mathrm{H} 13$ & $\mathrm{H} 14$ & $\mathrm{M} 1$ \\
\hline $\mathrm{H} 11$ & 1 & 2 & 3 & 1 & 0.3523 \\
$\mathrm{H} 12$ & $1 / 2$ & 1 & 2 & $1 / 2$ & 0.1898 \\
$\mathrm{H} 13$ & $1 / 3$ & $1 / 2$ & 1 & $1 / 3$ & 0.1078 \\
$\mathrm{H} 14$ & 1 & 2 & 3 & 1 & 0.3501 \\
\hline
\end{tabular}

4.2. Simulation Experiment of Supplier Selection. Using the function obtained above, the system optimization model is constructed as follows:

$$
\min \mathrm{NC}(r, C)=\frac{E[\mathrm{CB}]+E[\mathrm{CR}]+E[\mathrm{CD}]+E[\mathrm{CS}]+E[\mathrm{CO}]}{E[N]},
$$

where $E[\mathrm{CB}] \sim E[\mathrm{CO}]$ can be calculated by equations (15) to (19). Obviously, the above equation is a nonlinear optimization function with constraints, and its optimal solution can be determined by Matlab.

The purpose of the simulation is to analyze the influence of the system parameter variation on the optimal control strategy $r^{*}$ and $C^{*}$ and cost $\mathrm{NC}^{*}$ under the new environment. Referring to the commonly used model of demand and price multiplication, the relationship between the demand rate and supply interruption is defined as follows:

$$
\mu_{2}=\mu_{1} e^{\delta \rho /(1+\rho)},
$$

where $\delta$ represents the correlation between the demand and supply interruption. $\rho$ is the interruption intensity (i.e., the ratio of mean interruption time to supply time $\left(\theta_{1} / \theta_{2}\right)$. Similarly, the return rates and supply disruptions are defined as follows:

$$
\gamma_{2}=\gamma_{1} e^{-\varepsilon \rho /(1+\rho)},
$$

where $\varepsilon$ is the correlation between the returned goods and supply interruptions. Obviously, if $\delta$ and $\varepsilon$ are 0 , then $\mu_{1}=\mu_{2}, \gamma_{2}=\gamma_{1}$. It means that the demand and returns are independent of supply disruptions.

The influence of the change of the interrupt intensity and type is studied in the case of demand and interrupts. Here, the change of interrupt type is realized by adjusting the value of recovery rate $\theta_{2}$ for a given interrupt intensity $\rho=1$. Other parameters take the basic values, and the optimal results of the system are shown in Figures 2 and 3, respectively.

As can be seen from Figure 2, $r^{*}, C^{*}$, and $\mathrm{NC}^{*}$ increase with the increase of $\delta$ or $\rho$. The reason is that the increase of $\delta$ and $\rho$ leads to the increase of the demand rate $\mu_{2}$. To avoid
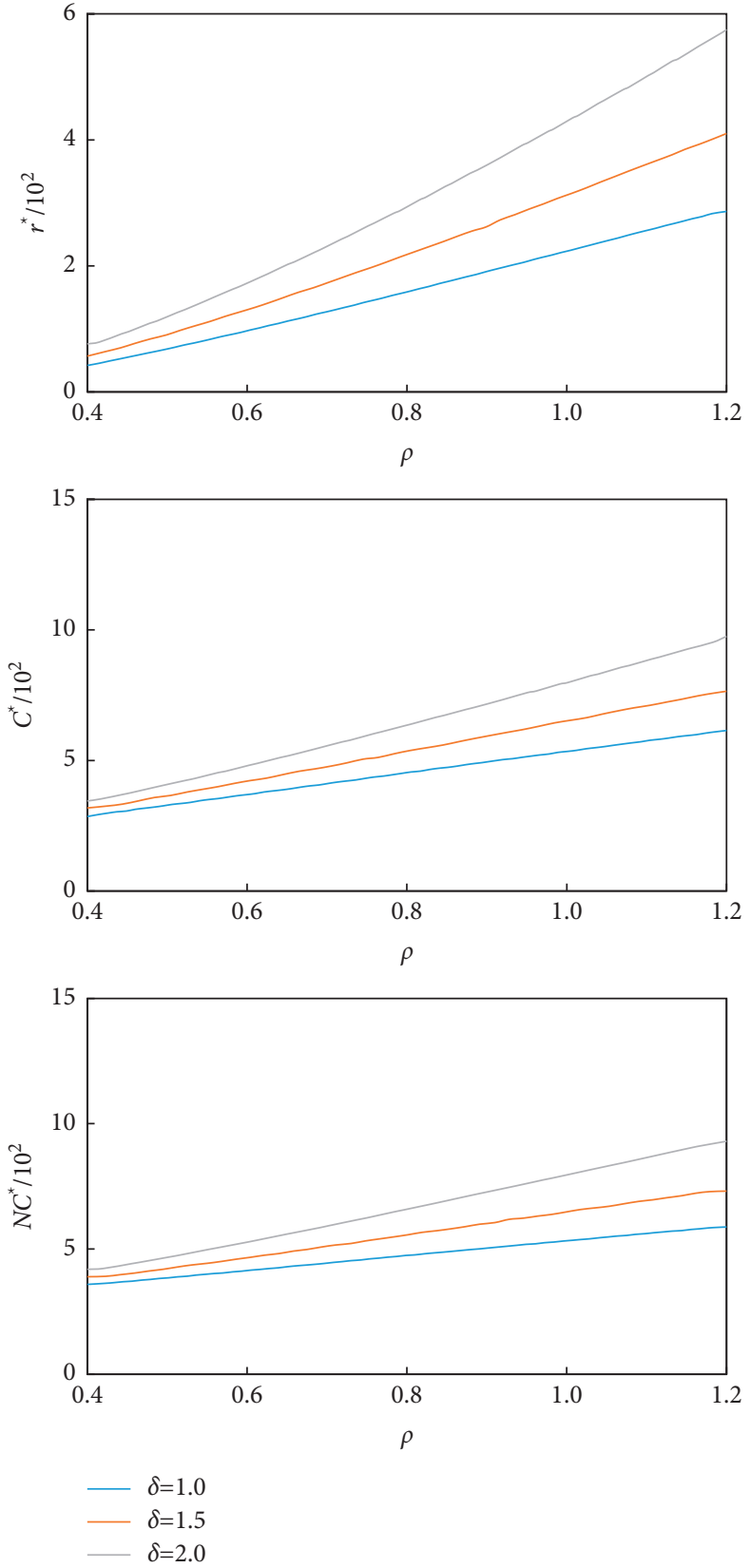

Figure 2: Optimal inventory strategy and cost corresponding to $\delta$ and $\rho$ changes.

large shortages and order costs, the retailers raise $r^{*}$ and $C^{*}$, resulting in higher $\mathrm{NC}^{*}$.

By comparing Figures 2 and 3, it can be seen that the change of interrupt type does not change the influence trend of $\delta$ on $r^{*}, C^{*}$, and $\mathrm{NC}^{*}$. However, with the increase of $\theta_{2}, r^{*}$, $\mathrm{C}^{*}$, and $\mathrm{NC}^{*}$ tend to decrease. The reason for this is that as $\theta_{2}$ changes from small to large, the interrupt type changes from low frequency with long duration to high frequency with short duration. Suppliers can recover more quickly from disruptions, and retailers do not need to keep high inventories to guard against shortages caused by disruptions. Therefore, both $r^{*}$ and $C^{*}$ decrease gradually, and $\mathrm{NC}^{*}$ also decreases. 

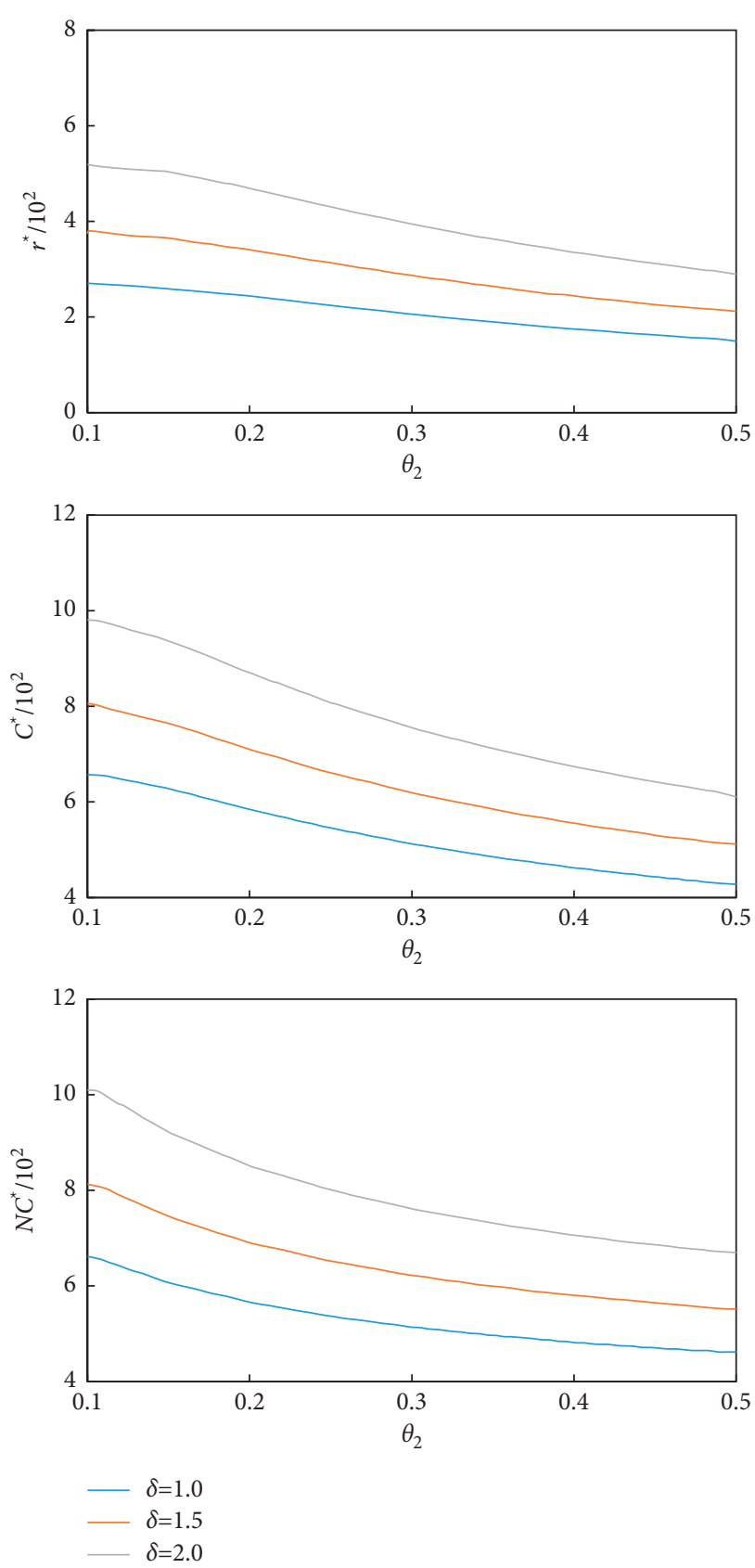

Figure 3: Optimal inventory strategy and cost corresponding to $\delta$ and $\theta_{2}$ changes.

\section{Conclusion}

Cross-border Internet of Things e-commerce is developing rapidly and has become an important development strategy for countries all over the world. However, the environment of cross-border Internet of Things e-commerce is becoming more and more complex, which is influenced by international factors, transportation, policies, and other factors. The supplier selection of e-commerce warehouse management is deeply analyzed based on the TRIZ theory, aiming to improve the rationality of inventory control. With expressing the change of the inventory level as a Markov-modulated Levy process, the model of the system's long-range average total cost ratio is constructed using the horizontal traversal, updating process, and multidimensional martingale theory. The feasibility of the system is verified by a simulation experiment. Future work will add the international trade situation, the climate, and other real-time change factors into the influence factors of the algorithm to make the model more consistent with the objective situation. The efficiency of the algorithm will be analyzed in future work.

\section{Data Availability}

The labeled datasets used to support the findings of this study are available from the corresponding author upon request.

\section{Conflicts of Interest}

The authors declare that they have no conflicts of interest.

\section{References}

[1] H. Xin and S. Zhang, "Research on data integrity of E-commerce platforms in the Internet of things under crossborder," in Proceedings of the 2021 International Conference on Control and Intelligent Robotics, pp. 646-651, Guangxi, China, June 2021.

[2] D. C. Valencia, V. A. Alejandro, L. Bran, M. Benjumea, and J. Valencia, "Analysis of e-commerce acceptance using the technology acceptance model," Scientific papers of the University of Pardubice. Series D, Faculty of Economics and Administration, vol. 45, 2019.

[3] Y. Wang, "A study on the application of unmanned distribution equipment in E-commerce environment," Management \& Engineering, no. 34, pp. 72-80, 2019.

[4] K. G. Chen, X. Y. Wang, and M. Huang, "Joint pricing and order quantities decisions for overconfident retailers with two demand cases," Control and Decision, vol. 33, no. 1, pp. 101-110, 2018.

[5] Y. Zhang, "Inventory and pricing management in probabilistic selling," P.hD Thesis, 2019, https://upcommons.upc.edu/ handle/2117/128189.

[6] N. H. Shah, U. Chaudhari, and M. Y. Jani, "Inventory control policies for substitutable deteriorating items under quadratic demand," Operations and Supply Chain Management: International Journal, vol. 12, no. 1, pp. 42-48, 2019.

[7] N. Tashakkor, S. H. Mirmohammadi, and M. Iranpoor, "Joint optimization of dynamic pricing and replenishment cycle considering variable non-instantaneous deterioration and stock-dependent demand," Computers \& Industrial Engineering, vol. 123, pp. 232-241, 2018.

[8] L. Feng, "Dynamic pricing, quality investment, and replenishment model for perishable items," International Transactions in Operational Research, vol. 26, no. 4, pp. 1558-1575, 2019.

[9] G. Santhi and K. Karthikeyan, "EOQ model for perishable products with price-dependent demand, pre and post discounted selling price," IOP Conference Series: Materials Science and Engineering, vol. 263, no. 4, Article ID 042133, 2017.

[10] A. Kumar and U. Chanda, "Economic order quantity under permissible delay in payments for new products in dynamic pricing-advertising condition," International Journal of Business Innovation and Research, vol. 13, no. 2, pp. 203-221, 2017. 
[11] P. Tekin and R. Erol, "A new dynamic pricing model for the effective sustainability of perishable product life cycle," Sustainability, vol. 9, no. 8, p. 1330, 2017.

[12] Z. Ning, X. Hu, Z. Chen et al., "A cooperative quality-aware service access system for social Internet of vehicles," IEEE Internet of Things Journal, vol. 5, no. 4, pp. 2506-2517, 2018.

[13] F. Lücker, R. W. Seifert, and I. Biçer, "Roles of inventory and reserve capacity in mitigating supply chain disruption risk," International Journal of Production Research, vol. 57, no. 4, pp. 1238-1249, 2019.

[14] J. Namdar, X. Li, R. Sawhney, and N. Pradhan, "Supply chain resilience for single and multiple sourcing in the presence of disruption risks," International Journal of Production Research, vol. 56, no. 6, pp. 2339-2360, 2018.

[15] M. Kamalahmadi and M. M. Parast, "An assessment of supply chain disruption mitigation strategies," International Journal of Production Economics, vol. 184, pp. 210-230, 2017.

[16] M. M. Parast and M. Shekarian, "The impact of supply chain disruptions on organizational performance: a literature review," Springer Series in Supply Chain Management, vol. 7, pp. 367-389, 2019.

[17] Y. C. Tsao, P. V. R. P. Raj, and V. Yu, "Product substitution in different weights and brands considering customer segmentation and panic buying behavior," Industrial Marketing Management, vol. 77, pp. 209-220, 2019.

[18] J. Liu, H. Zhou, and J. Wang, "The coordination mechanisms of emergency inventory model under supply disruptions," Soft Computing, vol. 22, no. 16, pp. 5479-5489, 2018.

[19] A. Hamidieh and M. K. Fazli, "A possibilistic reliable and responsive closed loop supply chain network design model under uncertainty," Journal of Advanced Manufacturing Systems, vol. 16, no. 4, pp. 317-338, 2017.

[20] I. Belski, "TRIZ thinking heuristics to nurture future generations of creative engineers," Australasian Journal of Engineering Education, vol. 24, no. 2, pp. 86-97, 2019. 